\title{
GETTING INVOLVED IN RESEARCH: A GUIDE FOR INSPIRED UNDERGRADUATES
}

Eureka

Volume 3, Number 1 (2012)

\section{Christopher R. Madan' \& Yvonne Y. Chen²}

1. Department of Psychology, 2. Centre for Neuroscience, University of Alberta

Most undergraduates know that the professors that teach their classes are often also researchers. But what exactly do they research? More importantly, what is research? Most departments in the Faculty of Science have research courses, not just at the 400-level, but sometimes at the 200- and 300-levels as well. Now, you're probably wondering what do students do in these classes, in research, and how can you get involved? I'm glad you asked...

\section{How can undergraduates contribute to research?}

Chris: There are many ways that you, as an undergraduate, can get involved in research. The two main ways are to take a research course or to volunteer.

Research courses. If you think you might be interested in going into research as a career, you shouldn't wait until graduate school to find out if research really is right for you. Most department in the Faculty of Science offer "individual studies courses" to undergraduates. In these courses you work one-on-one with a professor or graduate student on a particular project of theirs and learn the background for that research project, as well as how to actually *do* research. If you work with them for a term or two, you may even come up with your own research ideas and try and see if your professor would be interested in doing the study with you.

Volunteering. If you are thinking of doing a research course, but it's already into the term... that doesn't mean you have to wait until the next academic term to get involved. Most professors would be glad to take you on as a volunteer, and give you a chance to see how research is done before you completely dive in.

Roles and responsibilities. If you're either in a research course, or just a volunteer, usually you'd be expected to attend the weekly lab meetings organized by the professor who is supervising you. Usually these are meetings with the rest of the professor's research group and involve discussing a relevant research article, talking about the research project you are currently working on, and/or giving a short update on the research you have done in the last

\section{About the Authors}

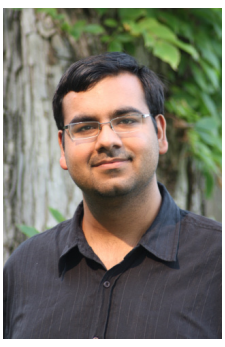

Christopher Madan first became involved in research in the second-year of his undergraduate career and is now a PhD candidate in the Department of Psychology. His research interests focus primarily on how memory is enhanced for rewarding and emotional events, and in particular how reward and emotion can influence the learning of associations. He is also interested in several other topics, including decision-making, mental imagery, and visual perception. He can be reached at cmadan@ualberta.ca.

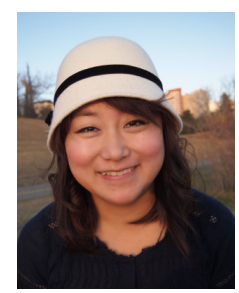

week. You are also expected to meet with the professor regularly (especially if you're doing a research course), as well as reading papers suggested by the professor. Usually some kind of data collection and analysis work is also required, but the methods used will vary greatly across the sub-fields that exist within science.

\section{Finding your passion}

\section{Yvonne: Choosing a field.}

On average, university undergraduate students in North America change their majors 3 times during the span of post secondary education. Half of the students actually do not finish their undergraduate degrees in 4 years. If you are not sure what you should do in your life, you are not alone!

If you were to ask me in my first year of university, "where do you see yourself in four years?", I can tell you without a doubt, my answer would not have been research. I came to university to study art and design. Design is such a subjective discipline. In order to create and design something truly inspirational, understanding human behaviour could be the key. While working on my designing crafts, I stumbled upon a psychology class. I liked the subject, but I wasn't particularly passionate about it, at least not until I found cognitive neuropsychology. It was the winter of my 3rd year in university, and I fell in love with every aspect of the course. This class was unique in the that I teamed up with my classmates to design and carry out a research experiment. I was excited to see the progress of the experiment and was curious to find out the results. The class changed my view of research. At the end of the semester, I approached the professor who taught the class, and he took me into his lab. I took 4 independent classes with him, and started my journey of research.

The reason of telling you about my story is hoping to demonstrate to you that you could also benefit from undergraduate research as well. Involved in undergraduate research is not as difficult as you may have imagined.

\section{Find your interest, find you passion.}

Learn from your peers. I am sure you make friends in your classes. The reason that you are taking same classes (besides filling up your prerequisites) is that you might be interested in the same subjects. Talk to them, find out what they do for classes and other school activities. You might stumble upon something might interests you.

Trying things out. Using a quote from a movie: "Life is like a box of chocolates. You never know what you're 
gonna get". How would you know what kind of chocolate is your favorite without trying any? Go out there and try all the chocolate if you can, and then you might know you like milky one more than the dark one or something else. Then choose the one you like the best! If none of them is your pick, don't stop! Keep looking till you find the one you love! It is the same to career choices or school major choices. First year students should take all those interesting courses to open their eyes, and then you can choose to specialize in one. Sometimes, it might take few tries before you might something that truly interests you.

\section{Your professors are researchers too!}

Yvonne: It can be a very scary thing to approach someone in the position of the research. Especially the only connection that you might have to the person would be the class you took, where you might be sitting at the back row, looking over almost 200 students and listening to the professor lecture over the speaker. Approach someone in the research might be easier than you might imagine.

It is very important before you approach anyone, do research on them: that might includes their research interest, recent publications, and current research projects. One hand, you can find a good match with your interests and the right professor; on the other hand, the knowledge you have about the professor would also give the professor a good first impression.

Find a good match. If you have previously taken a course with a professor, you might already have some ideas where their research interests lay. In some cases, you might find that their research interest might not be a good fit to yours. You can try to talk them and ask them for referral to other professors that might match your interests. Department websites would be a good place to begin your search. Each department website has a section for current professors, along with their research profiles. By reading them over should give you some ideas which professor you would like to approach. Things to keep in mind is that not everyone would have exact same interests as yours, the best way is to find someone that have interest that close to yours and might be able to provide the means to the kinds of research you want to do. Some department hosts "meet the prof night". It is a mixer between students and professors where you can meet the professors from that field and find out more about their research in a less format setting.

Get help. This year, University of Alberta launched Undergraduate Research Initiative (URI). It helps to facilitate undergraduates who want to get involved in research. They host free seminars, online database of undergraduate research opportunities.

Chris: Most university professors don't just teach undergraduates classes. In fact, this is very little of what they do! If you are interested in research, and have some idea of what field you want to go into, look up what kind of research your professors do. Most students usually don't have a good idea of what kind of research they are really interested in, but you probably can narrow it down a bit: Do you like chemistry or psychology? Computer science or geology? Physics or genetics? As long as you can choose a general field, you can start figuring out what kind of research you want to do. From this point, go to the department's website and look up the faculty members and read the 1-2 line descriptions of their research that are posted there. A great place to start would be the professors of the classes you found most interesting already! There's no need to try and narrow down your research interests just yet. Take advantage of the fact that you don't have a very specific research interest yet and meet with a few professors and see what (and who) inspires you!

\section{Approaching a professor about working in their lab} Chris: Okay, so you read a but about a professor and think they might be interesting to work with. Now what?

There's no reason to be worried or scared... the professor you want to meet was in your position too at one point too. If you happen to be in a class of this particular professor, one option would be to go to their office hours (preferably not near exam time) and tell them that you think their research is interesting and talk to them about what they do. Office hours not near an exam are usually not particularly busy, so you should be able to talk with the professor a bit to give you a better idea of how you interact one-on-one, rather than just watching the professor teach a class.

If you're not in a class of the professor, or are more serious, email the professor and ask if you can meet with them about working in their lab. At this time be prepared to tell the professor which aspects of their research you find particularly interesting, but also be prepared to talk about what you hope to gain by working with them, and consider bringing a copy of your transcript (an unofficial copy is fine).

Yvonne: When it comes to approaching the professor. If you have never meet this person, "email - in person visit email" approach would be a best.

First email. Writing this email is like writing a cover letter for a job. There are few elements you need to include. 1) Where did you get hold of their email addresses. Maybe from a course you took, maybe from the department website, or someone refereed to you. 2) Some information about you. That could include your name, your year, your interests, your intension of approaching this professor and so on. You may want to keep this concise. 3) Set a time to meet. Suggest that you could like to meet in person to discuss this further in person. You could also include a resume/CV in your email, so they get a better idea about you.

In person visit. Be there on time, be there prepared. We talked the importance of researching the professor before hand to find a good match. The research you have done would prepare you for this meeting. You want to learn more about this professor and his/her research, and you might want to show that you can be a good fit for the lab. For example, you know some projects this professor has been working on. You can ask about a particular project, its progress and show your interests.

Follow up email. Hopefully, you had a good meeting with the professor. First, thank the professor for the 
opportunities. Then, if you two have agreed that you are going to try out few things in his/her lab, you can express your excitement of joining the lab. If you find out this might not be a good fit for you, and professor has suggested other contacts, you can thank the professor for those contacts, and keep them in loop as to if any of those contacts work out for you. If you did end up with one of the contacts this professor suggested. Don't forget to email and thank again. This will help you build some professional network. If there is not favorable outcome from this meeting, still thank the professor for this meeting.

\section{Welcome to the wonderful world of research!}

We genuinely hope our suggestions on how to get involved with research helped you. And, if everything works out, please send us an email at eureka@ualberta.ca and tell us your story, or just give us some feedback. We wrote this article for you, the undergraduate who is interested in research, and would love to hear how things went for you!

\section{Discover Careers in Science} CAPS offers:

- Job Postings

- Career advice and information

- Resume critiques and mock intervews

- Networking events with employers

- Job Shadow Opportunties

- Science Careers Lunch Series (Winter 2012)

- Funding for leadership and professional development

- Advice on applying to medical school and graduate studies

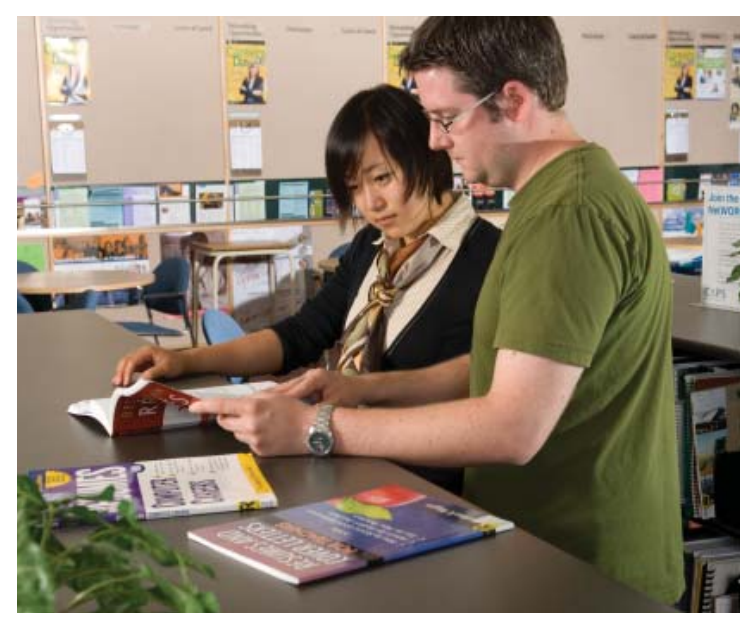

www.caps.ualberta.ca

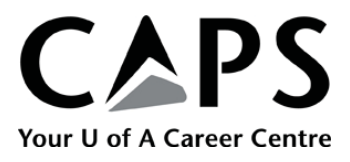

